\title{
Colorectal cancer in pregnancy mimicking tuberculosis
}

\author{
Leena Wadhwa $^{1} *$, Shilpi Nain ${ }^{2}$, Sonia Kataria ${ }^{2}$, Sunita Jindal ${ }^{3}$ \\ ${ }^{1}$ Associate Professor, ${ }^{2}$ Senior Resident, ${ }^{3}$ Senior Specialist, Department of Obstetrics \& Gynecology, ESI-Post Graduate \\ Institute of Medical Science \& Research, Basaidarapur, Delhi-110015, India
}

Received: 25 January 2013

Accepted: 22 March 2013

*Correspondence:

Dr. Leena Wadhwa

E-mail: drleena_123@yahoo.co.in

C 2013 Wadhwa L et al. This is an open-access article distributed under the terms of the Creative Commons Attribution License, which permits unrestricted use, distribution, and reproduction in any medium, provided the original work is properly cited.

\section{ABSTRACT}

Colorectal cancer in pregnancy is extremely rare and presentation may mimic symptoms of pregnancy or abdominal tuberculosis delaying diagnosis. We hereby report a case presenting to us in late pregnancy misdiagnosed as a case of abdominal tuberculosis.

Keywords: Colorectal cancer, Pregnancy, Abdominal tuberculosis

\section{INTRODUCTION}

Diagnosis of colorectal cancer in pregnancy is a challenge. Common presenting symptoms of colorectal cancer include abdominal pain, constipation, vomiting, anemia and rectal bleeding; most of these symptoms might be attributed to tuberculosis or pregnancy itself and be overlooked and diagnosis may be delayed. ${ }^{1,2}$ Most cases of colorectal cancer are diagnosed later in pregnancy when more widespread metastasis has occurred. $^{2}$

\section{CASE REPORT}

Patient X, a female aged 30 year, G3P2L1 was admitted at 31 weeks gestation with complaints of chronic diarrhea and pain in abdomen. She had prior two vaginal deliveries. She had history of loose motions and pain abdomen since first trimester of pregnancy. She was suspected of having inflammatory bowel pathology at 16 weeks and was managed conservatively. There was no history of vomiting, fever, rectal bleeding, anemia, jaundice, diabetes and hypertension. Patient was empirically started on ATT by her primary physician at 17 weeks of pregnancy in view of lump in right lumbar and iliac fossa suspecting abdominal tuberculosis. Patient had been on ATT for the last 4 months. On General examination her vitals were stable. There was no lymphadenopathy. On per abdomen examination; fundal height corresponded to 32 weeks of gestation with regular fetal heart sounds. After admission she was started on intravenous fluids and injectable antibiotics (metronidazole) but there was no relief. All routine antenatal investigations were normal. Upper abdomen ultrasound was normal. There was no family history of colorectal, endometrial, breast, or ovarian cancer. In view of chronic nature of illness and keeping the possibility of inflammatory bowel disease, she was advised colonoscopy which suggested stricture in rectum with indurated growth at $5 \mathrm{~cm}$ from anus and scope could not be negotiated further (Figure 1). Biopsy was taken from the growth; the histopathology report was mucinous adenocarcinoma rectum. After steroid cover, patient was taken up for cesarean section at 34 weeks gestation as the tumour was low down just $5 \mathrm{~cm}$ away from anus obliterating the birth canal. She delivered an alive premature baby which was shifted to nursery. Intraoperatively, multiple small $0.5 \times 0.5 \mathrm{~mm}$ seedlings were seen over parietal peritoneum, lower part of the uterus and sigmoid colon suggestive of peritoneal metastasis. Postoperative period was uneventful.

Patient CECT done after cesarean in the post-op period revealed malignant mass lesion involving rectum, anal canal and rectosigmoid region with surrounding fat stranding and involvement of bilateral levator ani and 
piriformis muscle with narrowing of bilateral lower ureter with resulting bilateral hydronephrosis with lymph nodes in bilateral perirectal, obturator and iliac group.

In view of advanced stage cancer, patient was referred for palliative radiotherapy and chemotherapy. Despite efforts to improve her condition, she expired after three months of diagnosis.

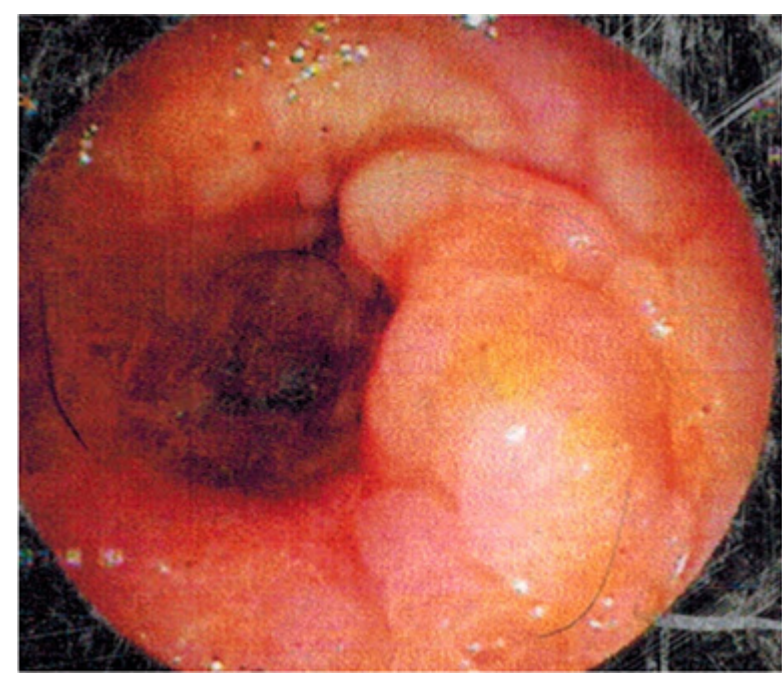

Figure 1: stricture in rectum with indurated growth.

\section{DISCUSSION}

Colorectal cancer in pregnancy is extremely rare. Cruveilhier reported the first case of rectal carcinoma in pregnancy in $1842 .{ }^{1}$ Cancer incidence has been estimated at approximately 1 in every 1000 pregnancies. ${ }^{3}$ The mean age of diagnosis reported in a survey was 31 years. ${ }^{4}$

Diagnostic dilemmas can arise posing a significant problem as symptoms of colorectal cancer are nonspecific and may easily be attributed to intestinal tuberculosis which accounts for the majority of extra pulmonary cases. ${ }^{5}$ Both have similar nonspecific symptoms which include chronic abdominal pain, weight loss, diarrhea, nausea, vomiting, and fever. Physical findings of colorectal cancer such as chronic signs of illness, malnutrition, tenderness, distended abdomen and palpable mass also mimic intestinal tuberculosis. ${ }^{5,6}$ In our case the diagnosis was delayed as the young pregnant patient, on basis of symptoms and signs was started on anti-tubercular therapy. Intestinal tuberculosis can masquerade colon cancer and the diagnosis should be based on overall considerations, including clinical manifestations, colonoscopy findings, and biopsy. On colonoscopy, intestinal tuberculosis mainly invades the ileocecal area and presents as a transverse ulcer and diagnosis is confirmed by granulomatous lesion on histopathology.

Inflammatory bowel disease is a precursor of colorectal carcinoma. If a patient has a chronic history of gastrointestinal symptoms, the decision for colonoscopy and biopsy to confirm the diagnosis should be taken earlier and the procedure is safe in pregnancy.

The management of colorectal cancer in pregnancy involves a multidisciplinary team involving obstetrician, neonatologist, gastroenterologist and medical oncologist. ${ }^{7}$ The choice of therapy generally depends on operability of tumour and period of gestation. If patient is diagnosed in early stage, colorectal surgery can be performed safely before 26 weeks of gestation. ${ }^{8}$ The mode of delivery is not affected by cancer, with the exception of a cesarean section owing to a distal tumour obstructing the birth canal or anterior rectal wall carcinoma. It has been proposed that colon cancer surgery can be done right after an uncomplicated cesarean section and the prognosis is better. ${ }^{9}$ Unfortunately, colorectal cancer in pregnancy in our case was diagnosed at a very advanced stage when surgical management was not possible and radiotherapy and chemotherapy were barely effective.

Adjuvant chemotherapy is suggested for stage III tumours; however, the risk and benefits should be discussed with the patient. ${ }^{10}$ The chemotherapeutic agents are usually highly teratogenic and have been associated with spontaneous abortion. Chemotherapy is safer during the second and third trimester of pregnancy, although there is an increase in the incidence of intrauterine growth retardation, prematurity. ${ }^{8}$

Adjuvant radiotherapy is used in the management of rectal cancer. Radiation therapy to the pelvis is not recommended during pregnancy because of the potential harm to the fetus. Pelvic radiation can be considered after delivery.

Pregnant women with colorectal cancer generally have a poor prognosis. Early diagnosis and early stage of disease along with immediate and appropriate treatment might enable the patient to have better life although no patient with colorectal cancer in pregnancy reported in the literature has survived longer than 5 years.

\section{CONCLUSION}

Colorectal carcinoma is a rare but devastating event during pregnancy. Because presentation can mimic with the signs and symptoms of TB or pregnancy, diagnosis is often delayed. Meticulous evaluation can enable early diagnosis and treatment. The disease if diagnosed early, surgical treatment can be done and patient's life can be prolonged. Advanced disease mandates palliative chemoradiotherapy after adequate patient counseling.

\author{
Funding: None \\ Competing interests: None declared \\ Ethical approval: Not required
}




\section{REFERENCES}

1. Cruveilhier JJ. Anatomie pathologique du corps humaine. Vol. 2. Paris, France: JB Baillière.1829; 7 10 .

2. Woods JB, Martin JN Jr, Ingram FH, Odom CD, Scott-Conner CE, Rhodes RS. Pregnancy complicated by carcinoma of the colon above the rectum. Am J Perinatol 1992;9:102-10.

3. Donegan WL. Cancer and pregnancy. CA Cancer $\mathbf{J}$ Clin 1983;33:194-214.

4. Bernstein MA, Madoff RD, Caushaj PF. Colon and rectal cancer in pregnancy. Dis Colon Rectum 1993;36:172-8.

5. Kangeyan N, Webster S, Sanyal A, Beukenholdt R. Tuberculosis in pregnancy-Diagnostic dilemma. Open Journal of Obstetrics and Gynecology 2012;2:174-5.

6. Yu SM, Park JH, Kim MD, Lee HR, Jung P, Ryu $\mathrm{TH}$, Choi SH, Lee IS. A case of sigmoid colon tuberculosis mimicking colon cancer. J Korean Soc Coloproctol 2012;28:275-7.

7. Kitoh T, Nishimura S, Fukuda S, Hirabuki S, Kaganoi J, Tokunaga $\mathrm{Y}$, et al. The incidence of colorectal cancer during pregnancy in Japan: report of two cases and review of Japanese cases. Am J Perinatol 1998;15:165-71.

8. Girard RM, Lamarche J, Baillot R. Carcinoma of the colon associated with pregnancy: report of a case. Dis Colon Rectum 1981;24:473-5.

9. Walsh C, Fazio VW. Cancer of the colon, rectum, and anus during pregnancy. The surgeon's perspective. Gastroenterol Clin North Am 1998;27:257-67.

10. Cohen-Kerem R, Railton C, Oren D, Lishner M, Koren G. Pregnancy outcome following nonobstetric surgical intervention. Am J Surg 2005;190:467-73.

DOI: $10.5455 / 2320-1770$. ijrcog20130625

Cite this article as: Wadhwa L, Nain S, Kataria S, Jindal S. Colorectal cancer in pregnancy mimicking tuberculosis. Int J Reprod Contracept Obstet Gynecol 2013;2:226-8. 